\title{
Superficial radial neuropathy: an unobserved etiology of chronic dorsoradial wrist pain
}

\author{
Emmanuel Kamal Aziz Saba(i)
}

\begin{abstract}
Background: Superficial radial neuropathy is considered an uncommon cause of chronic dorsoradial wrist pain. Its clinical diagnosis is usually missed. The purpose of the research was to investigate the existence of superficial radial neuropathy as a cause of chronic dorsoradial wrist pain. The study included 98 upper limbs obtained from 72 patients [58 women (80.6\%)] with a primary complaint of chronic dorsoradial wrist pain and 91 asymptomatic upper limbs obtained from 63 apparently healthy individuals [46 women (73.0\%)] as a control group. Clinical assessment and superficial radial nerve conduction study were done.

Results: No significant differences between patients and control group were present regarding sex and age. Among the participated patients, there were 29 upper limbs (29.6\%) from 26 patients (36.1\%) who had superficial radial neuropathy proved clinically and electrophysiologically. From them, three patients (11.5\%) had bilateral superficial radial neuropathy. It was the solitary cause of chronic dorsoradial wrist pain in 15 upper limbs (51.7\%) from 13 patients (50\%). The remaining patients were associated with other musculoskeletal wrist conditions. The most common associated local wrist pathology was de Quervain's disease in 8 upper limbs (27.6\%) from 8 patients (30.8\%).
\end{abstract}

Conclusions: Superficial radial neuropathy is common among patients with chronic dorsoradial wrist pain and should be considered in the differential diagnosis.

Keywords: Cheiralgia paresthetica, Chronic dorsoradial wrist pain, Superficial radial nerve, Superficial radial neuropathy

\section{Background}

Wrist pain is a common complaint for many patients. There are many etiologies attributed for the development of chronic dorsoradial wrist pain [1]. It is usually due to musculoskeletal problems as de Quervain's disease, ganglion, joint sprain, and arthritis. However, superficial radial neuropathy is a less common neurological cause for chronic dorsoradial wrist pain [2-4].

Superficial radial neuropathy is a pure sensory neuropathy $[5,6]$. It is known as cheiralgia paresthetica or

Correspondence: emadaziz55@yahoo.com; jppp_10@yahoo.com Present address: Physical Medicine, Rheumatology and Rehabilitation Department, Faculty of Medicine, Alexandria University, Alexandria, Alexandria Governorate 21131, Egypt (c) The Author(s). 2021, corrected publication 2021. Open Access This article is licensed under a Creative Commons Attribution 4.0 International License, which permits use, sharing, adaptation, distribution and reproduction in any medium or format, as long as you give appropriate credit to the original author(s) and the source, provide a link to the Creative Commons licence, and indicate if changes were made. The images or other third party material in this article are included in the article's Creative Commons licence, unless indicated otherwise in a credit line to the material. If material is not included in the article's Creative Commons licence and your intended use is not permitted by statutory regulation or exceeds the permitted use, you will need to obtain permission directly from the copyright holder. To view a copy of this licence, visit http://creativecommons.org/ licenses/by/4.0/.
Wartenberg disease $[7,8]$. It leads to pain and sensory disturbances over the dorsolateral surface of the hand and the dorsum of the lateral three and half fingers till the level of the distal interphalangeal joints without any muscle weakness. Tinel's sign could be present at the site of nerve entrapment by tapping the superficial radial nerve (SRN) along its course. This provocative maneuver supports the diagnosis with clinical history and examination. Associating feature is increasing the symptoms by wrist ulnar deviation giving a false-positive Finkelstein's test and Eichoffs test provided that there is no de Quervain's disease [2, 9-12]. These maneuvers stretch the nerve, and the symptoms increase if the nerve is irritated [2, 9-11]. Superficial radial neuropathy could be due to many causes $[8-11,13]$.
Springer Open 
The SRN is one of the two terminal branches of the radial nerve. The nerve roots of the SRN are cervical (C) 6 and C7 nerve roots. It descends down the forearm deep to the brachioradialis muscle on the lateral side of the radial artery over the radial bone. In the distal forearm, the nerve becomes superficial. It travels subcutaneously next to the radius. Subsequently, it is susceptible to injury. It is easily compressed by tight watch straps, bracelets, and handcuffs or traumatized. It enters the hand passing superficial to the anatomical snuff box tendons on the dorsolateral aspect of the wrist. Its territory is the lateral two thirds of the dorsum of the hand and the dorsum of the lateral three and half fingers till the level of the distal interphalangeal joints (Figs. 1 and 2) [14].
Although textbooks mention superficial radial neuropathy in the differential diagnosis of chronic dorsoradial wrist pain, there are scanty studies in literature which assessed this issue [4,9]. It is frequently underdiagnosed source of chronic dorsoradial wrist pain [9]. However, it is usually mentioned in the literature as case reports $[7,10,15]$. The purpose of the research was to investigate the existence of superficial radial neuropathy as a cause of chronic dorsoradial wrist pain.

\section{Methods}

This cross-sectional study included 98 upper limbs obtained from 72 patients with a primary complaint of chronic dorsoradial wrist pain. The research included 91 asymptomatic upper limbs obtained from 63 apparently

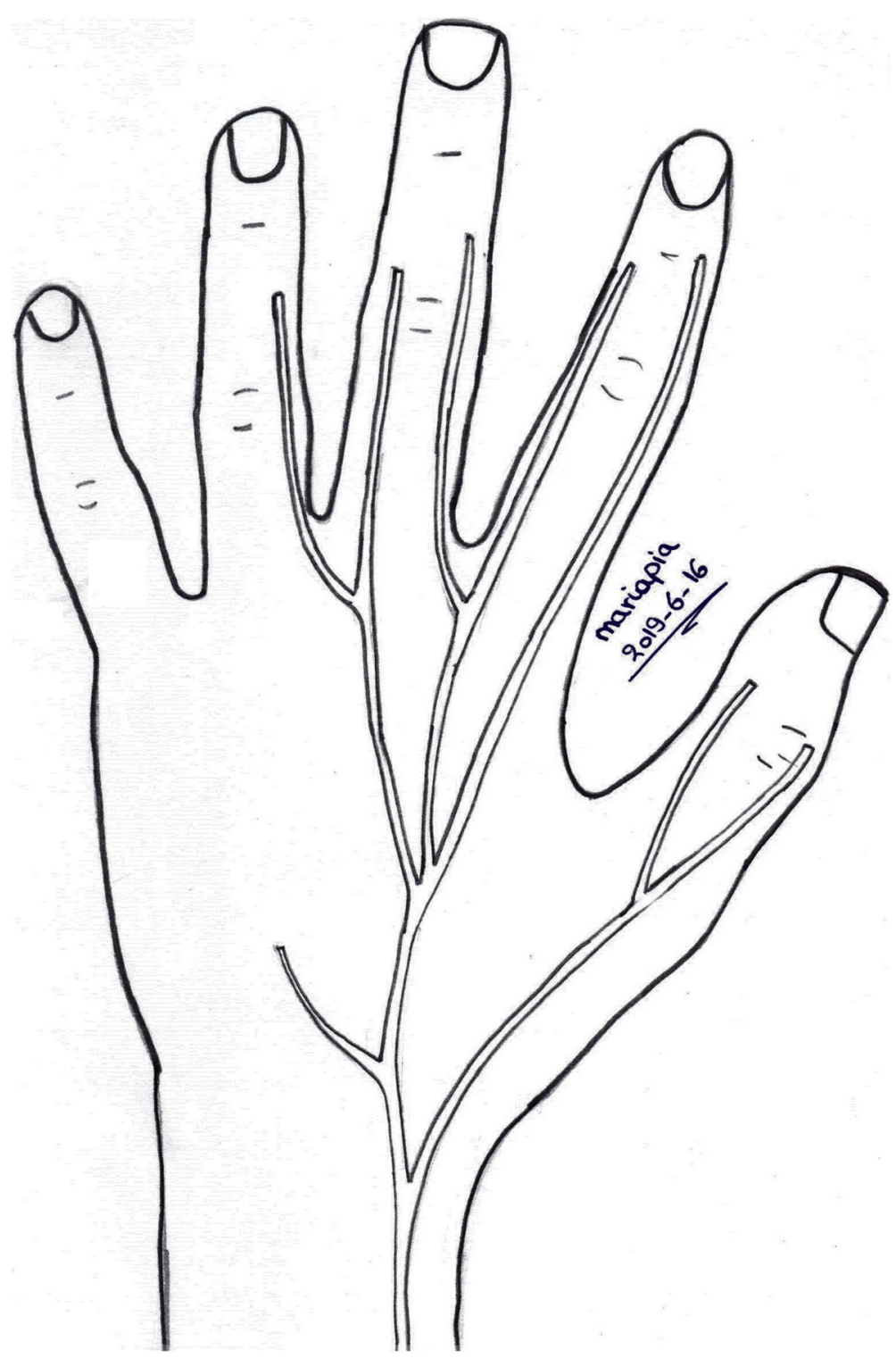

Fig. 1 An illustration representing the terminal anatomical course of superficial radial nerve [14] 


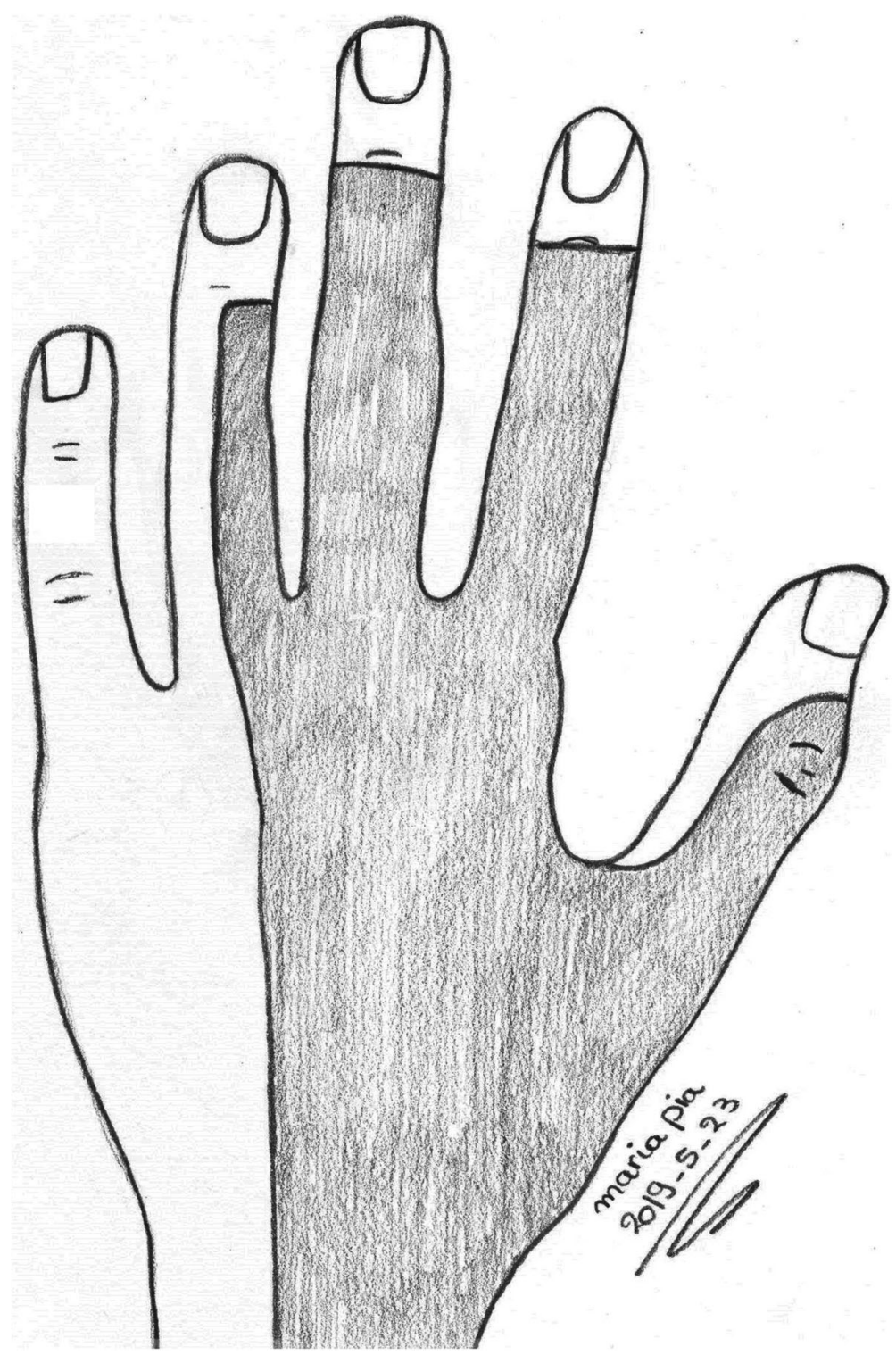

Fig. 2 An illustration representing the sensory territory of superficial radial nerve [14]

healthy individuals as a control group. They were selected randomly from those attending the clinic of the researcher's department. The inclusion and exclusion criteria are illustrated in Fig. 3. The participants received an explanation regarding the research and gave an informed consent. The local Ethics Committee accepted the research.

Demographic data collection and anthropometric measurements including body mass index (BMI) assessment were collected [16]. The presence of any burning pain, paresthesia, or numbness over the sensory territory of SRN was asked for. Severity of the dorsoradial wrist pain was measured using visual analog scale (VAS) (0 indicated no pain while 10 indicated extreme intolerable pain) [17]. Clinical examination was done which included musculoskeletal and neurological examination. The presence of any objective sensory alteration (hypoesthesia or anesthesia) in the territory of SRN was documented [4]. Tinel's sign was assessed by tapping the SRN within the area of the radial styloid process to an area about $10 \mathrm{~cm}$ proximal to the wrist on the lateral aspect of the forearm where the SRN pierce the deep fascia to be in the subcutaneous tissue $[9,11]$. Finkelstein's test was done. It was done as follows: ulnar deviation of the wrist while grasping the thumb in flexion by the examiner. This test was positive, if dorsoradial wrist pain appeared or increased with this maneuver [2, 4, 911]. Eichoff's test was done. It was done as follows: the patient clenched his or her thumb in a fist, then the examiner deviated the wrist ulnarly. This test was 


\section{Study inclusion and exclusion criteria}

\section{Inclusion criteria The presence of chronic dorsoradial wrist \\ pain of more than three months which did not \\ improve or partially improved by \\ conservative measures whether medical \\ therapy or physical therapy.}

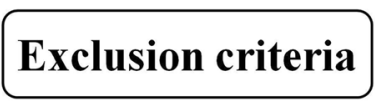

Endocrine disorders.

Metabolic disorders.

Neurological disorders as radial neuropathy,

other entrapment neuropathies, peripheral

neuropathy and cervical radiculopathy.

Fig. 3 The inclusion and exclusion criteria of the study

positive, if dorsoradial wrist pain appeared or increased with this maneuver $[4,9,11,12]$.

Neurophysiological assessment was done using a Nihon Kohden Neuropack S1 MEB-9400 unit with a twochannel machine (Nihon Kohden Corp., Japan). SRN sensory conduction antidromic study was performed. Details of the technique are illustrated in Fig. 4 [6, 13, 18, 19].

Criteria for diagnosing superficial radial neuropathy is tabulated in Table 1 [2, 4, 9-11, 13, 20]. Patients were classified into two groups depending on the existence of superficial radial neuropathy. Patients with superficial radial neuropathy were considered group I, while group II included patients without superficial radial neuropathy.

The data was analyzed using the SPSS software (version 17). Descriptive measures and analytic measures were used. Student's t-test, analysis of variance test (ANOVA), Pearson chi-square test, and Fisher's exact test (if needed) were used. Bonferroni's multiple comparison test (post hoc analysis) was done if required. Statistical significant was obtained for any $P<0.05$. The cut-off values of the neurophysiological parameters were calculated by using the mean \pm two standard deviations (SD) as appropriate.

\section{Results}

The study included 98 upper limbs with chronic dorsoradial wrist pain obtained from 72 patients [58 women (80.6\%)]. There were 26 patients (36.1\%) with bilateral complaint. Their mean age was $40.45 \pm$ 12.16 years and ranged from 19 to 68 years. The control group consisted of 91 asymptomatic upper limbs obtained from 63 apparently healthy individuals [46 women $(73.0 \%)]$. Both upper limbs of 28 apparently healthy individuals (44.4\%) were assessed. Their mean age was $42.04 \pm 10.07$ years and ranged from 19 to 63 years. No statistically significant differences were present between the two groups regarding sex $(P=$ $0.299)$ and age $(P=0.410)$. The clinical characteristics of the two groups are tabulated in Table 2 .

The reference cut-off values of the SRN sensory nerve action potential (SNAP) parameters obtained from the control subjects were as follows: peak latency $(\mathrm{PL}) \leq 2.9$ $\mathrm{ms}$, conduction velocity $(\mathrm{CV}) \geq 47.1 \mathrm{~m} / \mathrm{s}$, and SNAP amplitude $\geq 10 \mu \mathrm{V}$. Side-to-side SNAP amplitude ratio was obtained from 28 subjects who had bilateral SRN sensory conduction study. Its mean value was $0.78 \pm$ 0.15 . While the cut-off value of side-to-side SNAP amplitude ratio was $\geq 0.5$. Figures 5 and 6 illustrate SRN SNAPs.

Patients with superficial radial neuropathy constituted group I, while patients without superficial radial neuropathy constituted group II (Fig. 7). Eight patients (11.1\%) with bilateral chronic dorsoradial wrist pain had superficial radial neuropathy unilaterally. Group I consisted of 29 upper limbs (29.6\%) from 26 patients (36.1\%) who had superficial radial neuropathy proved clinically and electrophysiologically. Group II consisted of 69 upper limbs (70.4\%) from 54 patients (75\%) who had no superficial radial neuropathy (Fig. 7).

Among group I, there were three patients (11.5\%) who had bilateral superficial radial neuropathy. The SRN SNAP was unobtainable in five upper limbs (17.2\%) of four patients $(15.4 \%)$ in group I. No patients had motor symptoms or muscle weakness by clinical examination of the upper limbs.

Comparison between the two patients' groups and control group regarding clinical characteristics and SRN sensory conduction study parameters are shown 


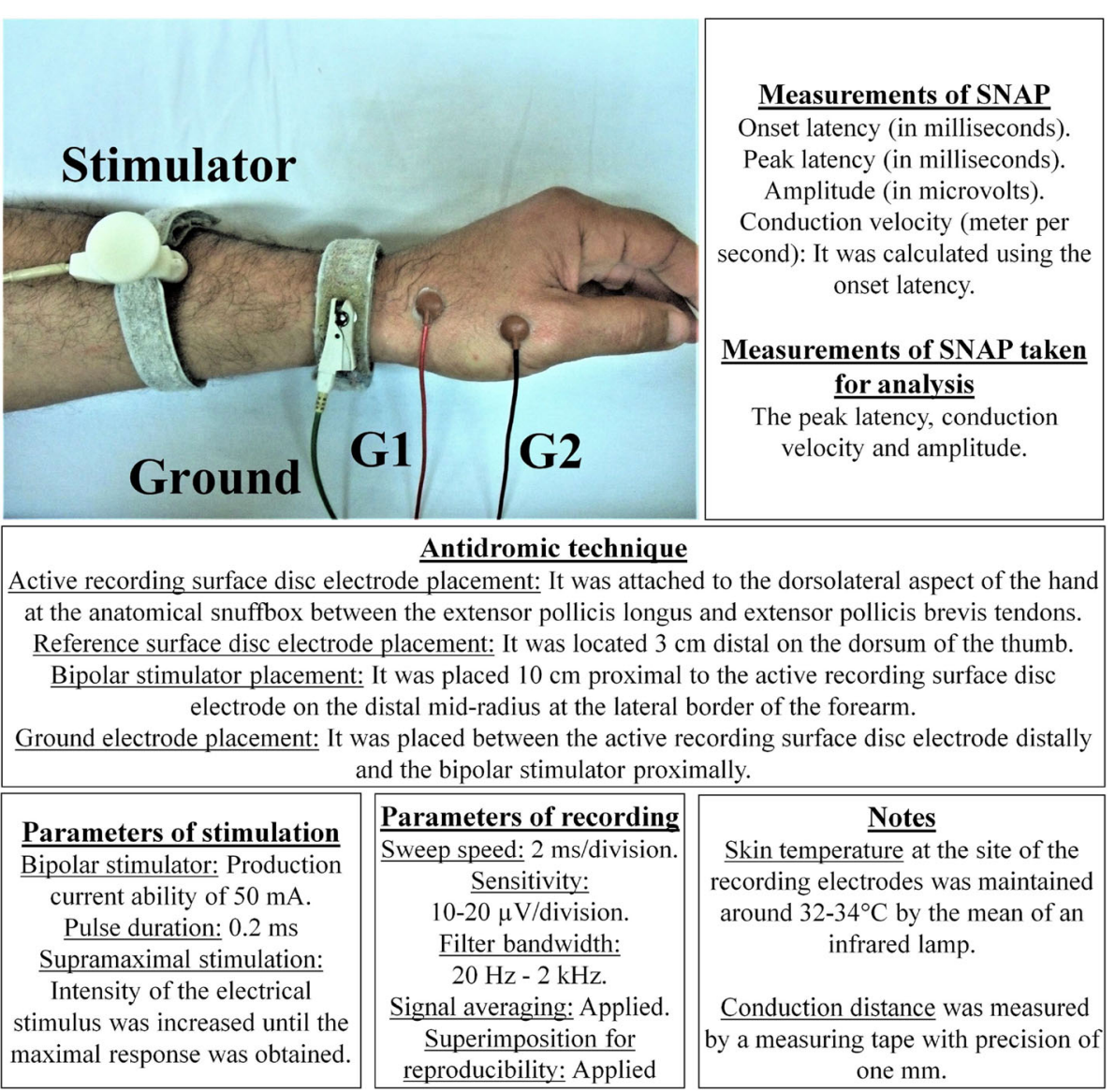

Fig. 4 Illustration of the superficial radial nerve sensory conduction study using an antidromic technique. It shows the stimulation and recording positions $[6,13,18,19]$. Ground, ground electrode; G1, active recording surface disc electrode; G2, reference surface disc electrode; Stimulator, electrical bipolar stimulator; SNAP, sensory nerve action potential; mA, milliampere; ms, millisecond; $\mu \mathrm{V}$, microvolt; $\mathrm{Hz}$, Hertz; kHz, kilohertz; $\mathrm{mm}$, millimeter

in Table 3. Statistically significant differences were present between the three groups in respect to different parameters of SRN SNAP. The SRN SNAP PL was significantly delayed among group I patients in comparison to group II patients and control group. Also, SRN SNAP CV was significantly slowed among group I patients in comparison to group II patients and control group. The SRN SNAP amplitude was significantly reduced among group I patients in comparison to group II patients and control group (Table 3).

The final diagnosis of patients in the study is demonstrated in Table 4. Among group I patients, superficial radial neuropathy was the solitary cause of chronic dorsoradial wrist pain in 15 upper limbs (51.7\%) from 13 patients (50\%). It was associated with other local wrist pathologies in the remaining group I patients. The most common pathology was de Quervain's disease in eight upper limbs (27.6\%) from eight patients (30.8\%).

\section{Discussion}

Superficial radial neuropathy is a potential etiology of chronic dorsoradial wrist pain $[4,5,21]$. However, it was considered a rare condition [5]. It is usually underrecognized etiology of chronic dorsoradial wrist pain. Its symptoms are usually subjective; subsequently, it is usually under-diagnosed [15].

Among our patients with chronic dorsoradial wrist pain, superficial radial neuropathy was found in 29 upper limbs (29.6\%) obtained from 26 patients (36.1\%). Among those patients with superficial radial neuropathy (group I), it was the only diagnosis of chronic dorsoradial wrist pain in 15 upper limbs (51.7\%) of 13 patients (50\%). However, it was associated with other wrist pathology in the remaining 14 upper limbs $(48.3 \%)$ obtained from 13 patients (50\%). Despite that superficial radial neuropathy was considered a rare condition, its prevalence in this study could be an indication that it was an underestimated health problem among patients with chronic dorsoradial wrist pain. 
Table 1 Criteria for diagnosing superficial radial neuropathy $[2,4,9-11,13,20]$

\begin{tabular}{ll}
\hline Diagnosis of superficial radial neuropathy & Items \\
\hline Clinical diagnosis & - The presence of burning pain, paresthesia or numbness in the territory of the SRN. \\
& - The presence of objective sensory loss in the form of hypoesthesia or anesthesia in the \\
& territory of the SRN. \\
& - With or without the presence of positive Tinel's sign on the lower lateral aspect of the forearm. \\
& - False-positive Finkelstein's test and/or false-positive Eichoff's test were considered associating \\
& features provided that there is no de Quervain's disease. \\
& The electrophysiological abnormalities in the SRN SNAP included the following: \\
Confirmation by the results of the sensory & - Absence SNAP response. \\
conduction study of the SRN. & - Delayed PL (regarding the calculated cut-off value obtained from the control group). \\
& - Slowed CV (regarding the calculated cut-off value obtained from the control group). \\
& - Reduced SNAP amplitude (regarding the calculated cut-off value obtained from the control \\
& group). \\
& - When the results of the SRN sensory conduction study were within the reference cut-off value, \\
& side-to-side SNAP amplitude ratio of less than 50\% was considered abnormal.
\end{tabular}

SRN Superficial radial nerve, SNAP Sensory nerve action potential, $P L$ Peak latency, CV Conduction velocity.

Superficial radial neuropathy could be due to many causes. It could be an entrapment neuropathy at its fascial penetration point. The entrapment could occur at the site of emergence of the nerve from beneath the edge of the brachioradialis tendon at the site of piercing the deep fascia to be subcutaneously between the brachioradialis tendon and extensor carpi radialis longus tendon [2]. This could be due to pinching the nerve by the brachioradialis and extensor carpi radialis longus tendons or even between the two slips of a split brachioradialis tendon [22]. It could be due to SRN stretching without any obvious structural changes. Repeated forceful pronation and supination of the forearm especially with wrist adduction results in SRN compression

Table 2 Clinical characteristics of the patients and control groups

\begin{tabular}{|c|c|c|c|c|}
\hline Clinical characteristics & $\begin{array}{l}\text { Patients group } \\
(\mathrm{n}=98 \text { upper limbs obtained from } \\
72 \text { patients) } \\
(m e a n \pm S D)\end{array}$ & $\begin{array}{l}\text { Control group } \\
(n=91 \text { upper limbs obtained from } 63 \\
\text { healthy individuals) }{ }^{c} \\
(m e a n \pm S D)\end{array}$ & $\begin{array}{l}\text { Test of } \\
\text { significance }\end{array}$ & $P$ \\
\hline Women $^{a}$ & $58(80.6)$ & $46(73.0)$ & $\left(X^{2}\right) 1.080$ & 0.299 \\
\hline Age (years) & $40.45 \pm 12.16$ & $42.04 \pm 10.07$ & (t) 0.827 & 0.410 \\
\hline Side (right/left) ${ }^{a}$ & $56(57.1) / 42(42.9)$ & $39(42.9) / 52(57.1)$ & $\left(X^{2}\right) 3.852$ & $0.059^{\circ}$ \\
\hline \multicolumn{5}{|l|}{ Anthropometric measures } \\
\hline Height $(\mathrm{cm})$ & $162.15 \pm 7.73$ & $163.19 \pm 9.18$ & (t) 0.718 & 0.474 \\
\hline Weight (kg) & $80.31 \pm 15.80$ & $78.43 \pm 14.03$ & $(t)-0.721$ & 0.472 \\
\hline $\mathrm{BMI}\left(\mathrm{kg} / \mathrm{m}^{2}\right)$ & $30.53 \pm 5.55$ & $29.50 \pm 5.04$ & $(\mathrm{t})-1.126$ & 0.262 \\
\hline \multicolumn{5}{|l|}{ BMI category } \\
\hline Normal weight ${ }^{a}$ & $9(12.5)$ & 13(20.6) & $\left(X^{2}\right) 3.347$ & 0.341 \\
\hline Overweight $^{a}$ & $26(36.1)$ & 25(39.7) & & \\
\hline Obese $^{a}$ & $31(43.1)$ & 23(36.5) & & \\
\hline Morbid obese $\mathrm{a}^{\mathrm{a}}$ & $6(8.3)$ & 2(3.2) & & \\
\hline Duration of complaints (months) & $10.38 \pm 4.16$ & NA & NA & NA \\
\hline VAS assessment of wrist pain & $6.60 \pm 1.57$ & NA & NA & NA \\
\hline $\begin{array}{l}\text { Objective sensory loss at the } \\
\text { territory of the SRN }{ }^{\mathrm{a}}\end{array}$ & 29(29.6) & NA & NA & NA \\
\hline Elicited Tinel's sign a & $27(27.6)$ & NA & NA & NA \\
\hline Positive Finkelstein's test $\mathrm{t}^{\mathrm{a}}$ & $61(62.2)$ & NA & NA & NA \\
\hline Positive Eichoff's test ${ }^{a}$ & $70(71.4)$ & NA & NA & NA \\
\hline
\end{tabular}

$\mathrm{cm}$ centimeter, $\mathrm{kg}$ kilogram, $B M I$ body mass index, $m$ meter, VAS visual analogue scale, $S R N$ superficial radial nerve, $n$ number of upper limbs, $S D$ standard deviation, $\left(X^{2}\right)$ value of Chi-square test, $(t)$ value of Student's t-test, $N A$ not applicable.

$* P$ is significant at $<0.05$.

${ }^{\text {a } D a t a}$ are presented as [number (percentage)].

${ }^{\mathrm{b}}$ Bilateral upper limbs with chronic dorsoradial wrist pain were obtained from 26 patients (36.1\%).

'Bilateral upper limbs assessment was done in 28 apparently healthy individuals (44.4\%).

${ }^{d}$ Value of Fisher's Exact test. 

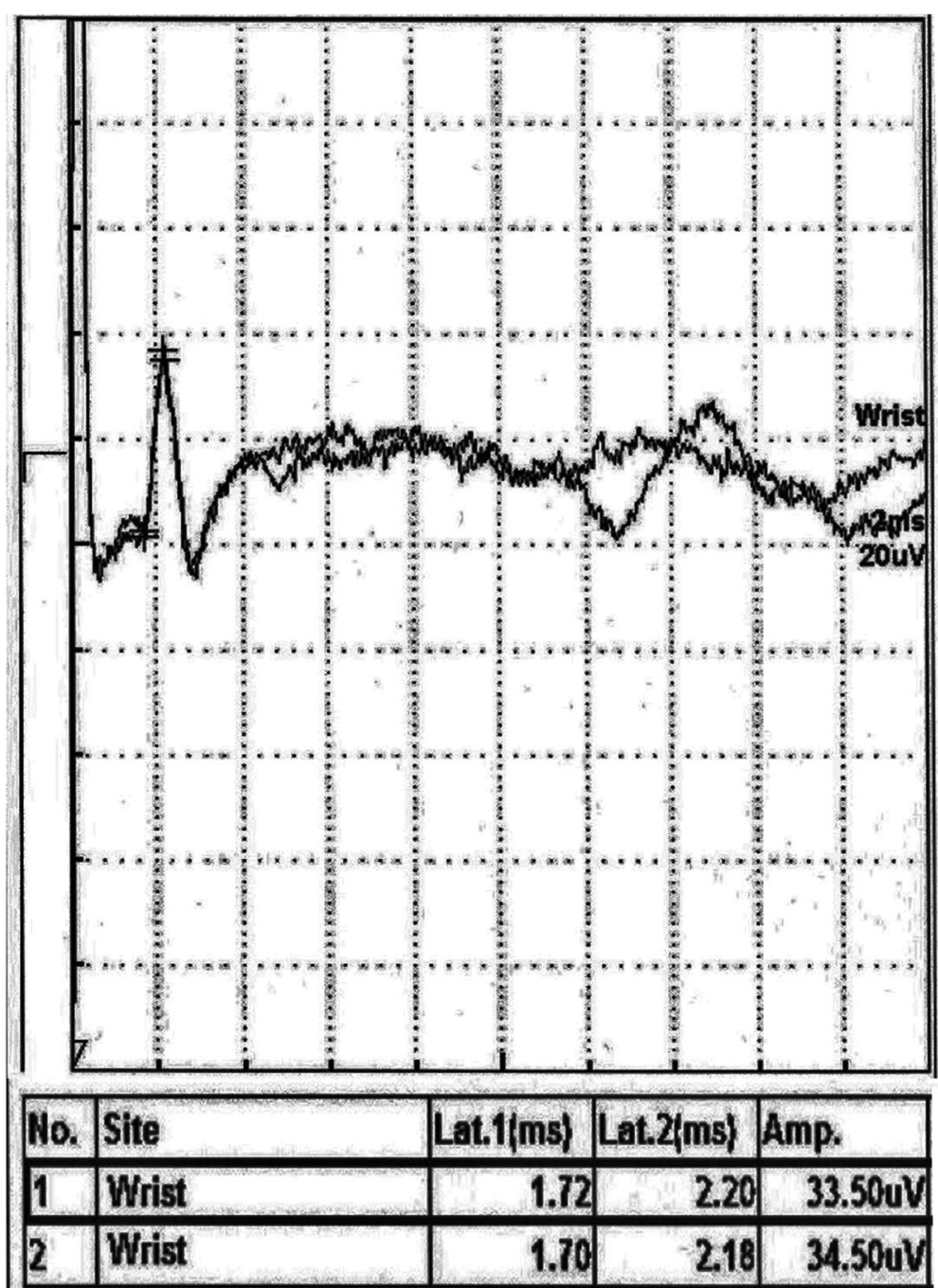

\begin{tabular}{|l|r|r|r|}
\hline Segment & Dist. $(\mathrm{mm})$ & Interval & MCV/misy \\
\hline 1 & 100 & $1.72 \mathrm{~ms}$ & 58.1 \\
\hline 2 & 100 & $1.70 \mathrm{~ms}$ & 58.8 \\
\hline
\end{tabular}

Fig. 5 Sample tracings show the superficial radial nerve sensory nerve action potentials of an apparently healthy individual

and stretching with subsequent nerve irritation. This could be due to job-related activities with repetitive pronation or flexion with wrist in ulnar deviation position [23]. This is considered a dynamic compression neuropathy [9].

Moreover, such neuropathy could be compression of the SRN distally due to external forces as compression by tight watch straps, tight bracelets, and tight handcuffs $[9,24-27]$. Compression of the SRN can be due to a space-occupying lesion as a ganglion cyst or even a lipoma or fibroma [28-32]. Due to the superficial course of the SRN, it is liable for local trauma. It could be due to direct blunt trauma or skin injuries and laceration to the lateral aspect of the distal forearm [33]. Blunt trauma can cause post-traumatic fibrosis and adhesions with post-traumatic neuroma formation associated with subcutaneous rupture of the SRN [33]. Superficial radial neuropathy could occur with de Quervain's disease by several mechanisms [24]. It could occur in patients with diabetes mellitus as a neurological complication among them or even idiopathic affection [34]. It could be due to compression by an enlarged union site callus of Colles' fracture at the distal radius bone [27].

Iatrogenic injury to the SRN could be due to orthopedic surgeries in the lower lateral forearm region as in surgical treatment of de Quervain's disease in the form of first dorsal compartment release $[35,36]$. Open 


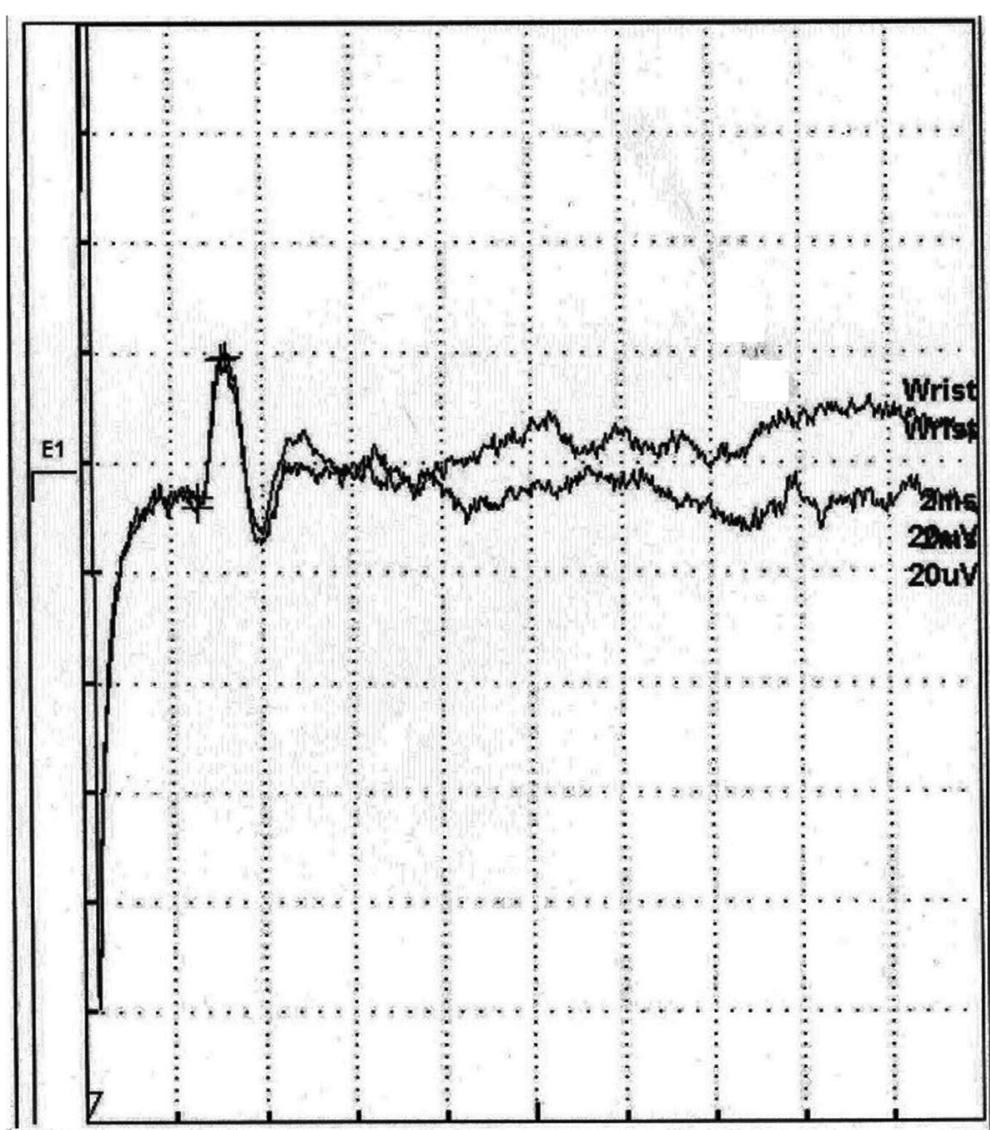

\begin{tabular}{|l|l|r|r|r|}
\hline No. & Site & Lat.1(ms) & Lat.2(ms) & Amp. \\
\hline 1 & Wrist & 2.58 & 3.10 & $25.30 \mathrm{uV}$ \\
\hline 2 & Wrist & 2.58 & 3.20 & $27.20 \mathrm{uV}$ \\
\hline
\end{tabular}

\begin{tabular}{|l|r|r|r|}
\hline Segment & Dist.(mm) & Interval & $\mathrm{NCV} / \mathrm{m} / \mathrm{s})$ \\
\hline 1 & 100 & $2.58 \mathrm{~ms}$ & 38.8 \\
\hline 2 & 100 & $2.58 \mathrm{~ms}$ & 38.8 \\
\hline
\end{tabular}

Fig. 6 Sample tracings show the superficial radial nerve sensory nerve action potentials of a patient with superficial radial neuropathy

reduction and internal fixation surgery for distal forearm bone fracture could lead to irritation of the SRN by stretch injury and direct contusion, as well as entrapment by bony spikes [27]. It could be due to K-wire insertion. It could be due to local corticosteroid injection for treatment of de Quervain's disease, or attempted placement of intravenous lines or shunts for hemodialysis when it is applied near the lateral aspect of the wrist. These result in nerve compression by scarring and fibrosis, and even direct nerve injury could take place $[23,24]$. It could be due to external compression by tight wrist splints (for example for carpal tunnel syndrome treatment) or even tight plaster cast in cases of forearm fracture [7, 8, 37].
The current study was in agreement with previous studies regarding the different etiological factors for development of superficial radial neuropathy $[5,9,11,24$, 25]. Braidwood described 12 patients with superficial radial neuropathy. Trauma was the cause in five patients (41.7\%), postoperative in two patients (16.7\%), tight wrist band in one patient $(8.3 \%)$ and idiopathic in four patients (33.3\%) [5]. Stahl and Kaufman described 15 patients with superficial radial neuropathy [9]. Trauma was the cause in three patients (20\%), job-related habitual movements in five patients (33.4\%), tight watch strap in two patients $(13.3 \%)$, tight plaster cast in two patients $(13.3 \%)$, tight handcuffs in one patient (6.7\%), and 

$\mathrm{n}=98$ upper limbs obtained from 72 patients.

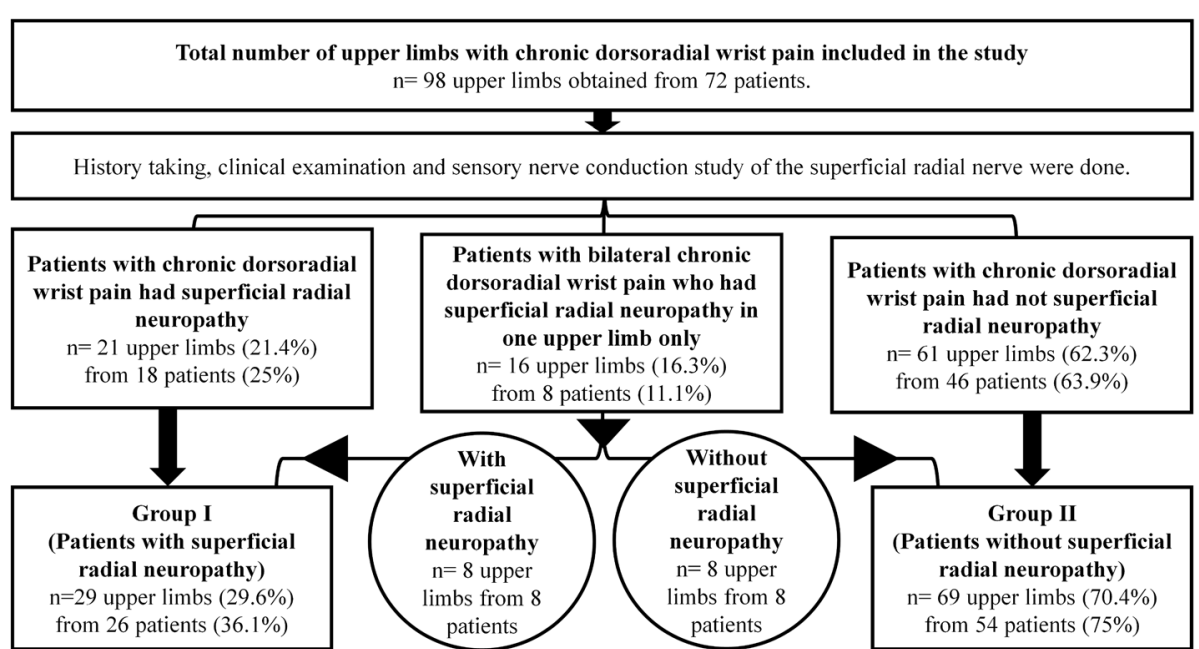

Fig. 7 An illustration representing the study flow chart of patients with chronic dorsoradial wrist pain. Among all participated patients, there were 26 patients (36.1\%) with bilateral complaint. There were eight patients (11.1\%) with bilateral chronic dorsoradial wrist pain who had superficial radial neuropathy unilaterally. Among group I, there were three patients (11.5\%) who had bilateral superficial radial neuropathy. Among group II, bilateral upper limbs affection were obtained from 15 patients (27.8\%). n, number

Table 3 Comparison between the two patients' groups and control group regarding different assessed parameters

\begin{tabular}{|c|c|c|c|c|c|}
\hline $\begin{array}{l}\text { Clinical characteristics and SRN } \\
\text { sensory conduction study } \\
\text { parameters }\end{array}$ & $\begin{array}{l}\text { Group I } \\
\text { ( } n=29 \text { upper limbs } \\
\text { obtained from } 26 \\
\text { patients) } \\
(\text { mean } \pm \text { SD) }\end{array}$ & $\begin{array}{l}\text { Group II } \\
\text { ( } n=69 \text { upper limb } \\
\text { obtained from } 54 \\
\text { patients) } \\
(\text { mean } \pm \text { SD) }\end{array}$ & $\begin{array}{l}\text { Control group } \\
\text { ( } \mathrm{n}=91 \text { upper limbs obtained } \\
\text { from } 63 \text { healthy } \\
{\text { individuals })^{\mathrm{d}}}^{(\text {mean } \pm S D)}\end{array}$ & $\begin{array}{l}\text { Test of } \\
\text { significance }\end{array}$ & $P$ \\
\hline Side (right/left) ${ }^{a}$ & $16(55.2) / 13(44.8)$ & $40(58.0) / 29(42.0)$ & $39(42.9) / 52(57.1)$ & $\left(X^{2}\right) 3.916$ & 0.141 \\
\hline Duration of complaints (months) & $11.00 \pm 4.73$ & $10.13 \pm 3.90$ & NA & $(\mathrm{t})-0.944$ & 0.348 \\
\hline VAS assessment of wrist pain & $6.58 \pm 1.65$ & $6.60 \pm 1.54$ & NA & (t) 0.064 & 0.949 \\
\hline $\begin{array}{l}\text { Objective sensory loss at the territory } \\
\text { of the SRN }{ }^{a}\end{array}$ & 29(100) & $0(0)$ & NA & NA & NA \\
\hline Elicited Tinel's sign ${ }^{a}$ & $27(93.1)$ & $0(0)$ & NA & $\left(X^{2}\right) 88.671$ & $\leq 0.0001^{*}$ \\
\hline Positive Finkelstein's test ${ }^{a}$ & 22(75.9) & $39(56.5)$ & NA & $\left(X^{2}\right) 3.250$ & $0.109^{* *}$ \\
\hline Positive Eichoff's test ${ }^{a}$ & $24(82.8)$ & $46(66.7)$ & NA & $\left(X^{2}\right) 2.591$ & $0.143^{* *}$ \\
\hline \multicolumn{6}{|c|}{ SRN sensory conduction study parameters } \\
\hline SNAP PL (ms) & $2.93 \pm 0.32^{e f}$ & $2.41 \pm 0.21^{f}$ & $2.46 \pm 0.20^{e}$ & (F) 49.387 & $\leq 0.0001^{*}$ \\
\hline $\operatorname{SNAP} C V(\mathrm{~m} / \mathrm{s})$ & $44.55 \pm 3.95^{\mathrm{ef}}$ & $55.69 \pm 5.01^{f}$ & $55.10 \pm 3.98^{e}$ & (F) 63.428 & $\leq 0.0001^{*}$ \\
\hline SNAP amplitude $(\mu \mathrm{V})$ & $21.50 \pm 11.66^{\mathrm{ef}}$ & $32.19 \pm 10.45^{f}$ & $30.81 \pm 10.41^{\mathrm{e}}$ & (F) 9.462 & $\leq 0.0001^{*}$ \\
\hline
\end{tabular}

SRN superficial radial nerve, VAS visual analogue scale, SNAP sensory nerve action potential, $P L$ peak latency, $m s$ millisecond, $C V$ conduction velocity, $\mathrm{m} / \mathrm{s}$ meter per second, $\mu V$ microvolt, Group / patients with superficial radial neuropathy, Group II patients without superficial radial neuropathy, $n$ number of upper limbs, SD standard deviation, $\left(X^{2}\right)$ value of Chi-square test, $(F)$ value of ANOVA test, NA not applicable, $(t)$ value of Student's t-test.

${ }^{*} P$ is significant at $<0.05$.

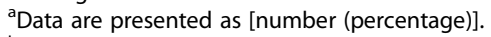

${ }^{\mathrm{b}}$ Bilateral upper limbs with superficial radial neuropathy were obtained from three patients (11.5\%). There were eight patients $(30.8 \%)$ with bilateral chronic dorsoradial wrist pain who had superficial radial neuropathy in one upper limb only.

${ }^{`}$ Bilateral upper limbs without superficial radial neuropathy were obtained from 15 patients (27.8\%). There were eight patients (14.8\%) with bilateral chronic dorsoradial wrist pain who had not superficial radial neuropathy in one upper limb while had it in the other upper limb.

${ }^{d}$ Bilateral upper limbs assessment was done in 28 apparently healthy individuals (44.4\%).

e Significant difference (post hoc test) between group I and control group regarding SNAP PL, CV and amplitude $(P<0.05)$.

${ }^{f}$ Significant difference (post hoc test) between group I and group II regarding SNAP PL, CV and amplitude $(P<0.05)$.

**Value of Fisher's Exact test. 
Table 4 Diagnosis of patients with chronic dorsoradial wrist pain in both patients' groups

\begin{tabular}{|c|c|c|}
\hline $\begin{array}{l}\text { Diagnosis of the chronic dorsoradial wrist } \\
\text { pain }\end{array}$ & $\begin{array}{l}\text { Group I } \\
(n=29 \text { upper limbs obtained from } 26 \\
\text { patients) } \\
{[n(\%)]}\end{array}$ & $\begin{array}{l}\text { Group II } \\
\text { (n=69 upper limb obtained from } 54 \\
\text { patients) } \\
{[n(\%)]}\end{array}$ \\
\hline $\begin{array}{l}\text { Superficial radial neuropathy with other } \\
\text { pathologies }\end{array}$ & $14(48.3)^{e}$ & NA \\
\hline De Quervain's disease & $8(27.6)$ & $39(56.5)^{k, l, m}$ \\
\hline First carpometacarpal joint $\mathrm{OA}$ & $3(10.36)^{f}$ & $13(18.8)^{1}$ \\
\hline $\begin{array}{l}\text { Status post-distal radial fracture (Colles' } \\
\text { fracture) }\end{array}$ & $2(6.9)$ & $6(8.7)$ \\
\hline Non-union scaphoid fracture & $0(0)$ & $1(1.5)$ \\
\hline Dorsal wrist ganglion & $1(3.44)$ & $7(10.1)$ \\
\hline Chronic wrist sprain & $0(0)$ & $5(7.2)^{\mathrm{m}}$ \\
\hline Intersection syndrome & $0(0)$ & $1(1.5)$ \\
\hline $\begin{array}{l}\text { Superficial radial neuropathy as the solitary } \\
\text { diagnosis }\end{array}$ & $15(51.7)^{\mathrm{g}}$ & NA \\
\hline \multicolumn{3}{|l|}{ Etiology of superficial radial neuropathy: } \\
\hline Tight handcuffs & $2(6.9)^{h}$ & NA \\
\hline Tight watch-strap & $2(6.9)$ & NA \\
\hline Tight bracelets & $1(3.44)$ & NA \\
\hline Job-related habitual activities ${ }^{\mathrm{a}}$ & $1(3.44)$ & NA \\
\hline Distal forearm blunt trauma & $1(3.44)$ & NA \\
\hline Distal forearm deep skin laceration ${ }^{b}$ & $1(3.44)$ & NA \\
\hline Distal forearm IV cannula & $1(3.44)$ & NA \\
\hline Idiopathic & $6(20.7)^{i}$ & NA \\
\hline
\end{tabular}

$O A$ osteoarthritis, $I V$ intravenous; Group I, patients with superficial radial neuropathy; Group II, patients without superficial radial neuropathy; n, number of upper limbs; $n(\%)$, number of upper limbs (percentage of upper limbs); NA, not applicable.

a Job-related habitual activities require repeated and frequent pronation and supination and/or frequent flexion and ulnar deviation of the wrist as with motor bike riders.

${ }^{\mathrm{b}}$ There was superficial radial nerve neuroma at the site of skin laceration scare in one upper limb (3.4\%).

'Bilateral upper limbs with superficial radial neuropathy were obtained from three patients (11.5\%). There were eight patients (30.8\%) with bilateral chronic dorsoradial wrist pain who had superficial radial neuropathy in one upper limb only.

dBilateral upper limbs without superficial radial neuropathy were obtained from 15 patients (27.8\%). There were eight patients (14.8\%) with bilateral chronic dorsoradial wrist pain who had not superficial radial neuropathy in one upper limb while had it in the other upper limb.

e Superficial radial neuropathy with other pathologies were present in both upper limbs of one patient (3.8\%).

${ }^{f}$ First carpometacarpal OA was present in both upper limbs of one patient (3.8\%).

${ }^{g}$ Superficial radial neuropathy as solitary diagnosis was present in both upper limbs of two patients (7.7\%).

${ }^{\mathrm{h}}$ Superficial radial neuropathy due to tight handcuffs was present in both upper limbs of one patient (3.8\%).

'Idiopathic superficial radial neuropathy was present in both upper limbs of one patient (3.8\%).

${ }^{k}$ De Quervain's disease was present in both upper limbs of five patients (9.3\%).

'De Quervain's disease with first carpometacarpal OA were present in the same upper limb of two patients (3.7\%).

${ }^{m}$ De Quervain's disease with chronic wrist sprain were present in the same upper limb of one patient (1.9\%).

idiopathic in two patients (13.3\%) [9]. Lanzetta and Foucher reported 52 upper limbs with superficial radial neuropathy obtained from 50 patients (two patients had bilateral affection) [11]. It was associated with de Qervain's disease in 26 upper limbs (50\%), dorsal wrist ganglion of the first dorsal compartment in two upper limbs (3.8\%), tight watch strap in eight upper limbs (15.4\%), work related in four upper limbs (7.7\%), and trauma in 13 upper limbs (25\%) [11]. Calfee et al. reported 25 upper limbs with superficial radial neuropathy from 23 patients [24]. It was associated with de Qervain's disease in 13 upper limbs (52\%), dorsal wrist ganglion in one upper limb (4\%), handcuffs in four upper limbs
(16\%), trauma in three upper limbs (12\%), and postoperative in four upper limbs (16\%) [24].

About $27.6 \%$ of patients in group I with superficial radial neuropathy were associated with de Quervain's disease. This was in agreement with previous studies $[9,11$, 24, 35, 38]. Stahl and Kaufman reported that 33\% of their patients with superficial radial neuropathy had associated other soft tissue rheumatism as de Quervain's disease [9]. De Quervain's disease is characterized by chronic inflammatory reaction leading to stenosing tenosynovitis of the first dorsal compartment tendons. This could be suggested that inflamed soft tissues 
surrounding the SRN could make the SRN to be inflamed consequently $[9,38]$. Chronic de Quervain's disease results in swelling and distension of the extensor retinaculum related to the first dorsal extensor compartment resulting in overstretching of the SRN [39]. The SRN could be adherent to the extensor retinaculum secondary to its swelling in chronic de Quervain's disease $[11,38,40]$. There is fibrosis with fibrocartilagenous metaplasia in the extensor retinaculum. Both abductor pollicis longus (APL) and extensor pollicis brevis (EPB) tendons become entrapped within the narrowed extensor compartment. This results in impairment of their normal sliding movement. Traction of the SRN could occur with wrist ulnar deviation due to limited APL and EPB tendon movement and sliding due to increased resistant to the tendon gliding movements within the stenosed first dorsal compartment [11, 38, 40].

The study agreed with Bun et al. regarding SRN SNAP PL [41]. It was in accordance with Bun et al. and Kona et al. regarding SRN SNAP amplitude [41, 42]. However, it was not in agreement with Echternach et al. regarding SRN SNAP CV and amplitude. In their study, SRN SNAP CV was faster and amplitude was larger than that reported in the present work [43]. The study was not agreed with Thakur et al. regarding SRN SNAP amplitude. In their work, SNAP amplitude was smaller than that in the present study [44]. These differences could be due to differences in the studied populations regarding age and race. Echternach et al. and Thakur et al. studied subjects who were younger than the control group of the current research [18, 19, 43, 44].

Managment of superficial radial neuropathy includes conservative and operative treatment. Conservative tratment includes rest, splinting, activity modifications with cessation of activities aggravating the pain, soft tissue mobilization, neurodynamic exercises, electroanalgesic current, anticonvulsant drugs for neuropathic pain, vitamin B complex supplementations, local injection of corticosteroid, and treating the underlying etiology $[2,9,23$, $24,29,45]$. Surgical treatment includes neurolysis. It is indicated for recalcitrant cases and involves decompression of the SRN from the radial styloid process [10, 24].

It is important to draw attention to the presence of superficial radial neuroapthy. It should be taken into consideration in dealing with patients with chronic dorsoradial wrist pain. Meticulous history taking and careful clinical examination in asscoaition with proper investigation in the form of electrohysiological study will help in the proper diagnosis of superficial radial neuroapthy whenever suspicion for its occurrence is present [11]. The symptoms of superficial radial neuroapthy are usually subjective. The clinical manifestations are usually unreliable, and its electrophysiological assessment is usually not routinely done [6].
This condition could be overlooked or unobserved as a local musculoskeletal disorder [9]. It is usually missed because its clinical manifestations are usually overlooked by the more common prevalence and more apparent clinical features of other dorsoradial wrist musculoskeletal disorders and injuries, which draw the attention of the treating physicians. Usually, its diagnosis is delayed because it is mistaken for other pathological conditions that are more common as de Quervain's disease [10, 28, 46]. According to the results of the current study, superficial radial neuropathy should not be considered a rare condition. It is present and should be serached for. As long as it is in the mind of the physician, it will be diagnosed easily and readily [47]. It should be taken into consideration when proper medical treatment for chronic dorsoradial wrist pain failed to improve the diagnosed condition as de Quervain's disease for example.

Superficial radial neuropathy must be searched for before surgical treatment of any dorsoradial musculoskeletal wrist pathology as de Quervain's disease or surgical excision of a dorsal wrist ganglion from the first dorsal compartment [11]. Because if it is present, it could result in persistence of patient's complaints following surgery.

Limitations of the research included the following: (I) the inclusion of relatively small number of male patients. Females are more common to suffer regional musculoskeletal disorders than males [48, 49]. (II) Musculoskeletal ultrasonography and neuromuscular ultrasonography to the dorsoradial wrist region were not performed. They could reveal causes of dorsoradial wrist pain as tenosynovitis, intersection syndrome, space-occupying lesions such as ganglion cyst, and neuroma of the SRN $[1,21]$. (III) This study was conducted in the Physical Medicine and Rehabilitation clinic only. It did not recruit patients from clinics of other specialties (example: Orthopedic Surgery clinics) where patients with chronic dorsoradial wrist pain could seek medical advice. Future studies should be conducted on a larger scale in collaboration with different specialities dealing with paitents with chronic dorsoradial wrist pain. This aims to verify the obtained results.

\section{Conclusions}

In conclusion, superficial radial neuropathy is common among patients with chronic dorsoradial wrist pain and should be considered in the differential diagnosis.

\section{Abbreviations \\ ANOVA: Analysis of variance test; APL: Abductor pollicis longus; BMI: Body mass index; C: Cervical; CV: Conduction velocity; EPB: Extensor pollicis brevis; OL: Onset latency; PL: Peak latency; SD: Standard deviation; SNAP: Sensory nerve action potential; SRN: Superficial radial nerve; VAS: Visual analog scale}

\section{Acknowledgements}

The author is grateful to Mariam Kamal Aziz Saba for her assistance in the statistical analysis. The author is grateful to Maria Kamal Aziz Saba for her assistance in the preparation of the figures. 


\section{Author's contributions}

The author (EKAS) contributed in the concepts, design, definition of intellectual content, literature search, clinical studies, data acquisition and analysis, manuscript preparation, editing and revision. The author read and approved the final manuscript.

\section{Funding}

The author received no specific funding for this work. The author declares that no financial or material support was provided by any parties and that there are no equity interests, patent rights, or corporate affiliations for this work. This research did not receive any specific grant from funding agencies in the public, commercial, or not-for-profit sectors. No sponsors or funders (other than the named author) played any role in study design, data collection, and analysis, decision to publish and preparation of the manuscript. All research facilities are available in our department for with no restrictions.

\section{Availability of data and materials}

The datasets used and/or analyzed during the current study are available from the corresponding author on reasonable request.

\section{Declarations}

\section{Ethics approval and consent to participate}

The local Ethics Committee of Faculty of Medicine, Alexandria University, Egypt (IRB NO:00007555-FWA NO: 00018699) approved the study. Date of approval:21/3/2019

Serial number: 0304287. A written informed consent was given by each participant.

\section{Consent for publication}

Consent for publication was given by each participant.

\section{Competing interests}

The author declares no competing interests.

Received: 3 April 2021 Accepted: 10 June 2021

Published online: 01 September 2021

\section{References}

1. Forman TA, Forman SK, Rose NE (2005) A clinical approach to diagnosing wrist pain. Am Fam Physician 72:1753-1758

2. Ruchelsman DE, Lee SK (2009) Neurovascular injuries of the hand in athletes. Curr Orthopaedic Pract 20:409-415

3. Liao JC, Chong AKS, Tan DMK (2013) Causes and assessment of subacute and chronic wrist pain. Singap Med J 54(10):592-598

4. Atzei A, Luchetti R (2004) Clinical approach to the painful wrist. In: Geissler WB (ed) Wrist arthroscopy, 1st edn. Springer-Verlag, New York, pp 185-195

5. Braidwood AS (1975) Superficial radial neuropathy. J Bone Joint Surg 57: 380-383

6. Preston D, Shapiro B (eds) (2013) Electromyography and neuromuscular disorders: clinical-electrophysiologic correlations, 3rd edn. Elsevier Saunders, Pennsylvania

7. Chodoroff G, Honet JC (1985) Cheiralgia paresthetica and linear atrophy as a complication of local steroid injection. Arch Phys Med Rehabil 66(9):637-639

8. Serçe A, Umay EK, Karaahmet OZ, Cakcı FA (2018) An unexpected side effect: Wartenberg syndrome related to the use of splint during carpal tunnel syndrome treatment. Turk J Phys Med Rehab 64(1):83-86

9. Stahl S, Kaufman T (1997) Chiralgia paresthetica - entrapment of the superficial branch of the radial nerve: a report of 15 cases. Eur J Plast Surg 20:57-59

10. Politylo J, Decina PA, Lopes AA (1993) Superficial radial neuropathy secondary to intravenous infusion at the wrist: a case report. J Can Chiropr Assoc 37(2):92-96

11. Lanzetta M, Foucher G (1993) Entrapment of the superficial branch of the radial nerve. Int Orthop 17:342-345

12. Ilyas AM, Ast M, Schaffer AA, Thoder J (2007) De Quervain tenosynovitis of the wrist. J Am Acad Orthop Surg 15:757-764

13. Scott KR (2010) Ulnar and radial nerves. In: Butler K, Morris J, Scott KR Simmons Z (eds) Neuroanatomy for nerve conduction studies. American Association of Neuromuscular and Electrodiagnostic Medicine, Rochester, pp 13-20
14. Agur AMR, Dalley AF (eds) (2017) Grant's atlas of anatomy, 14th edn. Philadelphia, Wolters Kluwer

15. Hu S, Choi J, Son B (2015) Cheiralgia paresthetica: an isolated neuropathy of the superficial branch of the radial nerve. Nerve 1(1):1-5

16. Agu AU, Esom EE, Anyaeji PS, Nzekwe KC, Chime SC, Ikele II et al (2019) Obesity indices and academic performance of medical students of lgbo extraction at College of Medicine, University of Nigeria. World J Med Sci 16(4):191-195

17. Gould D, Kelly D, Gammon J (2001) Visual analogue scale (VAS). J Clin Nurs 10:697-706

18. Saba EKA (2016) Electrophysiological study of the ulnar palmar cutaneous nerve in normal individuals. Egypt Rheumatol Rehabil 43:184-189

19. Saba EKA (2020) Electrophysiological study of posterior antebrachial cutaneous nerve in a sample of normal subjects. Egypt Rheumatol Rehabil 47:21. https://doi.org/10.1186/s43166-020-00007-4

20. Sindler HA, Dellon AL (1990) Nerve conduction studies in the superficial radial entrapment syndrome. Muscle Nerve 13:1-5

21. Shehab R, Mirabelli MH (2013) Evaluation and diagnosis of wrist pain: a case-based approach. Am Fam Physician 87(8):568-573

22. Turkof E, Puig S, Choi SS, Zoch G, Dellon AL (1995) The radial sensory nerve entrapped between two slips of a split brachioradialis tendon: a rare aspect of Wartenberg's syndrome. J Hand Surg 20A:676-678

23. Dellon AL, Mackinnon SE (1986) Radial sensory nerve entrapment in the forearm. J Hand Surg 11A:199-205

24. Calfee RP, Shin SS, Weiss APC (2008) Neurolysis of the distal superficial radial nerve for dysaesthesia due to nerve tethering. J Hand Surg Eur Vol 33E(2): $152-154$

25. Grant AC, Cook AA (2000) A prospective study of handcuff neuropathies. Muscle Nerve 23:933-938

26. Weinberg L, Spanger M, Tan C, Nikfarjam M (2015) Postoperative wrist watch-induced compressive neuropathy of the hand: a case report. J Med Case Rep 9:141

27. Tosun N, Tuncay l, Akpinar F (2001) Entrapment of the sensory branch of the radial nerve (Wartenberg's syndrome): an unusual case. Tohoku J Exp Med 193:251-254

28. Enescu RM, Tomek Al, Popescu M, Lascar I (2016) Lipoma of the proximal forearm with compression of the superficial radial nerve. Modern Med 223(14):64-70

29. Miralles JR, Cisneros LN, Escolà A, Fallone JC, Cots M, Espiga X (2016) Type a ganglion cysts of the radiocapitellar joint may involve compression of the superficial radial nerve. Orthopaedics Traumatol Surg Res 102:791-794

30. Lifchez SD, Dzwierzynski WW, Sanger JR (2008) Compression neuropathy of the radial nerve due to ganglion cysts. Hand 3(2):152-154

31. Spinner RJ, Mikami M, Desy NM, Amrami KK, Berger RA (2018) Superficial radial intraneural ganglion cysts at the wrist. Acta Neurochir 160:2479-2484

32. Chen IC, Chung-Yuh T, Tu-Sheng L (2005) Superficial radial nerve compression caused by a parosteal lipoma of proximal radius: a case report. Hand Surg 10(2-3):293-296

33. Boussakri H, Reckendorf GMZ (2015) Subcutaneous rupture of the superficial branch of the radial nerve at the wrist. A case report and review of literature. Chirurgie de la Main 34:141-144

34. Massey EW, O'Brian JT (1978) Cheiralgia paresthetica in diabetes mellitus. Diabetes Care 1:363-366

35. Arons MS (1987) De Quervain's release in working women: a report of failures, complications, and associated diagnoses. J Hand Surg [Am] 12:540-544

36. Huanmanop T, Agthong $\mathrm{S}$, Luengchawapong K, Sasiwongpakdee T, Burapasomboon P, Chentanez V (2007) Anatomic characteristics and surgical implications of the superficial radial nerve. J Med Assoc Thail 90(7):1423-1429

37. Thrush DN, Belsole R (1995) Radial nerve injury after routine peripheral vein cannulation. J Clin Anesth 7:160-162

38. Rask MR (1978) Superficial radial neuritis and de Quervain's disease: report of three cases. Clin Orthopedics 131:176-178

39. Chang KV, Hung CY, Ozcakar L (2015) Snapping thumb and superficial radial nerve entrapment in de Quervain disease: ultrasound imaging/guidance revisited. Pain Med 16(11):2214-2215

40. Rask MR (1979) Watchband superficial radial neurapraxia. JAMA 241:2702

41. Bun HR, Hwang MR, Kim DH, Kwon EH (2007) Nerve conduction study of the distal branches of the superficial radial nerve. J Korean Acad Rehab Med 31: $557-561$

42. Kona T, Suzukia C, Hottab R, Nukadab H, Babaa M, Tomiyamaa M (2017) Nerve conduction study for diagnosing injury in the superficial radial nerve. J Neurol Sci 381:496-497 
43. Echternach JL, Levy F (1985) Evaluation of sensory nerve conduction velocity testing of the superficial radial nerve. Phys Ther 65(4):470-473

44. Thakur D, Paudel BH, Jha CB (2010) Nerve conduction study in healthy individuals a preliminary age based study. Kathmandu Univ Med J 8(31): 311-316

45. Shacklock M (1995) Neurodynamics. Physiotherapy 81(1):9-15

46. Haller JM, Potter MQ, Sinclair M, Hutchinson DT (2014) Intraneural ganglion in superficial radial nerve mimics de Quervain tenosynovitis. J Wrist Surg 3(4):262-264

47. Saba EKA, El-Tawab SS, Sultan HA (2017) Medial calcaneal neuropathy: a missed etiology of chronic plantar heel pain. Egypt Rheumatol Rehabil 44: $147-152$

48. Rollman GB, Lautenbacher S (2001) Sex differences in musculoskeletal pain. Clin J Pain 17:20-24

49. Hagen KB, Bjorndal A, Uhlig T, Kvien T (2000) A population study of factors associated with general practitioner consultation for non-inflammatory musculoskeletal pain. Ann Rheum Dis 59:788-793

\section{Publisher's Note}

Springer Nature remains neutral with regard to jurisdictional claims in published maps and institutional affiliations.

\section{Submit your manuscript to a SpringerOpen ${ }^{\circ}$ journal and benefit from:}

- Convenient online submission

- Rigorous peer review

- Open access: articles freely available online

- High visibility within the field

- Retaining the copyright to your article

Submit your next manuscript at $\boldsymbol{\nabla}$ springeropen.com 